DOI: $10.17516 / 1997-1397-2021-14-6-805-814$

УДК 681.5

\title{
Numerical Modelling of Compression Cure High-Filled Polimer Material
}

\author{
Konstantin A. Chekhonin \\ Victor D. Vlasenko* \\ Computing Center of the Far Eastern Branch of the RAS \\ Khabarovsk, Russian Federation
}

Received 08.08.2021, received in revised form 10.09.2021, accepted 20.10.2021

\begin{abstract}
The article presents phenomenological constitutive relations for modeling the compression curing of a highly filled polymer medium, obtained in the framework of the mechanics of an almost incompressible viscoelastic solid using the modified Herrmann variational principle. The relations are based on the representation of the medium as a composition of a fluid and solidified material, taking into account the history of continuous nucleation and deformation of a new phase in the temperature range of phase transformations.

During the manufacturing process, different mechanisms lead to process-induced deformations and stresses. These mechanisms depend on thermal expansion, shrinkage, nonlinear viscoelastic properties of the material, and variation in local temperatures. In critical cases, these residual stresses can lead to initial degradation and up to failure of the material. A stable numerical algorithm for the problem's solution has been developed on the base of finite element method. Numerical investigation of the stress and deformation in system during the polymerization process has been carried out. The evolution of curing stresses in a singular zone of domain has been investigated.
\end{abstract}

Keywords: polymerization, high-filled polymer, finite element method, curing stress, viscoelasticity, variational theorem Herrmann.

Citation: K.A. Chekhonin, V.D. Vlasenko, Numerical Modelling of Compression Cure High-Filled Polimer Material, J. Sib. Fed. Univ. Math. Phys., 2021, 14(6), 805-814.

DOI: 10.17516/1997-1397-2021-14-6-805-814.

Reaction Injection molding (RIM) involves the impingement mixing and injection of the high viscosity high-filled composite material reactand into the mold, and the curing reaction within the mold. The injection molding process can be divided into thee major stages: filling, packing and solidification.

During the filling stage the pressure in the mold rises slowly, as the molten, non-Newtonian incompressible high-filled polymer spreads to fill the empty cavity. It is desirable to introduce more polymer into the cavity during the packing stage, in order to compensate for shrinkage during curing and cooling. The physical properties of injection molded articles are markedly affected by the temperature, pressure, and velocity fields that prevail in the mold cavity during the molding cycle. The resin properties, mold geometry, and molding conditions interact to produce the thermomechanical history experienced by the resin, which determines the microstructure distribution and, therefore, the ultimate properties of the molded article.

Let's consider the polymerization process of high-filled composite material (FCM) in the domain $\Omega$ shown in Fig. 1. The polymerization takes place at the preset on the casting mode

\footnotetext{
*vlasenko@as.khb.ru https://orcid.org/0000-0001-7782-4532

(C) Siberian Federal University. All rights reserved
} 
and central profile body (CPB) thermal treatment and is accompanied with transition from a liquid to a solid state. At the moment the volume taken up with the high-filled composite material, presents a reactor where complex physical-and-chemical and thermal physics processes take place. They are accompanied with mechanical phenomena related to the state transformations (changes) and shaping the structure of the consolidated high-filled composite material as well as the interaction of the coupling $(\sim 20 \%)$ and fine-dispersion filler $(\sim 80 \%)$.

The most complete description of the procedures taking place during the compression polymerization of FCM they connect with V. V. Bolotin's consolidation theory [1-3] that presents a three-component model of FCM: 1 - nonlinear elastic filler; 2, 3 - fixed and migratory binder. The filler and the fixed binder form a structure. The migratory binder is capable of being filtrated through the structure. When the induction time of exothermic polymerization reaction is over a three-dimensional molecular net begins to form in FCM, the link changes to highly elastic state while its migration in respect to the structure stops.

Because of thermal treatment and heat release of polymerization exothermic reaction the heterogeneous temperature and depth fields of transformation arise in the volume $\Omega$ (Fig. 1). The degree of their non-uniformity is increased when Frank-Kamenetzky [4] criterion goes up. When its values are small the polymerization proceeds in the mode of relatively uniform distribution in the volume of transformation depth (volume polymerization). And when its values are greater the reaction is completed first in the layers close to the casing and central profile body and then the polymerization front moves to the center of volume $\Omega$ (front polymerization). This phenomenon is similar to the process of burning of gas mixtures and is discovered comparatively not long ago for polymerized system $[5,6]$. It should be noted that the volume and front polymerization are not heterogeneous phenomena; they can be considered mutually transient alternatives of polymerization in the above-mentioned volume during the non-isothermal progress of reaction. Besides, the recently conducted research $[7,8,9]$ give ground to make a conclusion of principle concerning the possibility of bringing down the front polymerization mode to some equivalent mode of volume polymerization. From the point of view of influence of polymerization reaction conditions of the stress-and-deformed state (stress-deformation conditions ) of the polymerized FCM the difference of chemical and temperature shrinkage may be presented as a standard specifying the deviation degree of the volume polymerization mode.

To make the determinated mathematical analog of the polymerization process it is necessary to properly present the main comprising steps [3].

\section{Formulation of the problem (problem statement)}

The proposed here phenomenological approach to the complex account of volume polymerization FCM in the closed domain $\Omega$ (Fig. 1) is based on the extensive application of numerical methods and experimental data; the method of getting these data has already been tested [1, 8-19]. We believe that the change of the stressed-and-deformed state of the forming FCM does not influence the temperature and polymerizational fields in it. The account comprise two steps: to determine the changes in the coupled temperature and polymerisating fields and to define the stress-deformation conditions of the system (Fig. 1) based on the results of solving the first step. In the temperature-polymerization sub-problem the polymerized FCM is regarded as homogenous medium with uniformly distributed heat sources. The inner heat sources are made dependent on structural and phase transformations in FCM. The casing presents a thermally compliant thinwalled moment shell of rotation having definite conditions for fastening its flanges 


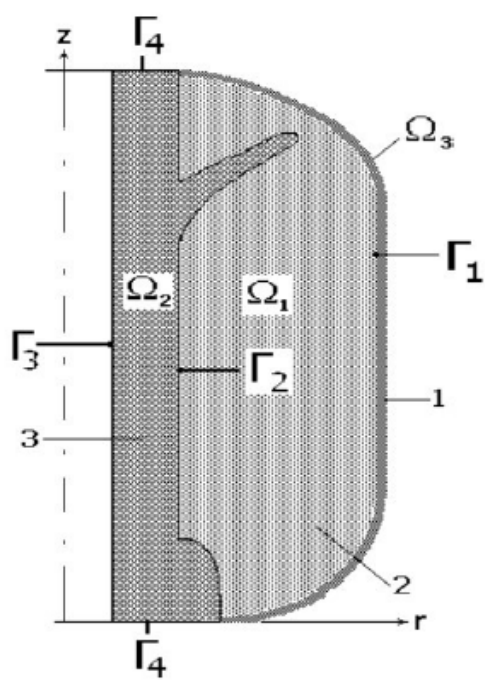

Fig. 1. Boundaries of the system: 1 - thin-walled shell of rotation; 2 - solidification FCM; 3 - central profile body; $\Gamma_{1}, \Gamma_{2}$ - contact boundary FCM with the shell and central body

upon the thermally compliant profile body (Fig. 1). They consider that the thermal properties of the system do not depend on the temperature, while in FCM on its structure as well. The polymerized FCM is a near-incompressible $(\nu \approx 0,5)$ thermo-polymerized ordinary viscous and elastic medium (the volume does not relax [8]), Poisson's ratio $(\nu)$ depends on structural changes in it $[9,13,17-19]$. Taking into account the introduced assumptions the mathematic modeling of the nonstationary problem of compression polymerization FCM in the domain $\Omega$ (Fig. 1) will consist of determining the $T$ - temperature, the degree of polymerization $\beta$, the component of a displacement vector $u_{i}$ and hydrostatic pressure function $H$ satisfying $[8-13,17,19,20]$ :

- equation of energy

$$
\rho c_{p} \frac{\partial T}{\partial t}=\nabla_{i} \lambda \nabla_{i} T+Q_{v}
$$

- equation macrocinetics of reaction polymerization FCM (kinetic law Malkin-Kamal [1])

$$
\frac{\partial \beta}{\partial t}=K(1-\beta)^{r}\left(1+c \beta^{l}\right),
$$

- the balance equations

$$
\nabla_{j}\left[\mu\left(2\left(\nu H-e_{T}\right) g_{i j}+\left(\nabla_{i} u_{j}+\nabla_{j} u_{i}\right)\right)-\Gamma_{i j}\right]+\rho F_{i}=0,
$$

with a condition of communication (distension)

$$
(1-2 v) H=\varepsilon_{i j} g_{i j}-3 e_{T},
$$

where $\mu=\mu_{0} \exp \left[a_{1}\left(\beta-\beta_{n}\right)-a_{2}\left(T-T_{n}\right)\right]-$ the Modules, $\mu_{0}, a_{1}, a_{2}, r, c, l$ - empirical constants [1], t - time, $1 \leqslant i, j \leqslant 3$

$$
\begin{gathered}
e_{T}=\alpha_{t} T-T_{n}-1 / 3\left(\alpha_{\beta}\left(\beta-\beta_{0}\right)+\alpha_{p}\right), \quad K=K_{0} \exp \left(-\frac{E}{R T}\right), \\
v=\left\{\begin{array}{l}
v_{0}=\frac{1}{2} \text { at } \beta_{0}<0.08 ; \\
v_{0}-\left[1-\exp \left(a_{3}\left(\beta-\beta_{0}\right)\right)\right] \text { at } \beta \geqslant \beta_{0},
\end{array}\right.
\end{gathered}
$$


$\alpha_{t}$ - linear coefficient of thermal expansion, $\alpha_{\beta}, \alpha_{p}$ - volumetric factors chemical reaction of polymerization and degree packing FCM ( $\alpha_{p}$ is necessary for creation of initial hydrostatic pressure in system ), $\beta_{0}$ - the degree solidification, at which FCM pass in to form by a gel a status (attributed to gelation), $\nu_{0}$ - Poisson's ratio FCM during all induction period of course of reaction polymerization $\left(\beta<\beta_{0}\right), \Gamma_{i j}$ - effective tensor relaxation shear stress with dependence of a spectrum time relaxation from temperature and degree of polymerization (we adapt the concept of thermo-rheological simple materials $[9,10,16]), \rho$ - density, $c_{\rho}$ - heat capacity at constant pressure, $F_{i}$ - components of a vector of volumetric forces, $a_{3}$ - empirical constant, $T_{n}, \beta_{n}$ - initial temperature and degree of solidification (polymerization), $g_{i j}$ - metric tensor, $K_{0}$ - constant speed of reaction, $E$ - activation energy of reaction polymerization, $R$ - universal gas constant, $\varepsilon_{i j}=\left(\nabla_{i} u_{j}+\nabla_{j} u_{i}\right) / 2$ - the strain tensor, $H$ - the hydrostatic pressure in the material (i.e. the hydrostatic part of the stress tensor [20]).

In the equation energy (1) capacities heat allocated are considered of proportional speed of change of a degree polymerization [1]

$$
Q_{v}=Q \frac{\partial \beta\left(x_{k}, t\right)}{\partial t}
$$

where $Q$ - thermal effect of reaction.

System of the equations (1)-(4) is closed initial $T(x, 0)=T_{n}, \beta(x, 0)=\beta_{n}$ and boundary conditions:

a) On the boundary of interface $\Gamma_{1}$ FCM with the shell (Fig. 1)

$$
T\left(x_{k}, t\right)=\phi_{0}\left(x_{k}, t\right), \quad u_{i}\left(x_{k}\right)=U_{i}^{0}\left(x_{k}\right), \quad \sigma_{n}=q_{i}^{0}, \quad i, k=\overline{1,3} .
$$

b) On the boundary of interface $\Gamma_{2}$ FCM with CPB is established contact conditions with friction (Coulomb's law) [16, 17, 21]

- on the part of boundary surface $\Gamma_{2}$, where $\sigma_{n}<0$

$$
\begin{gathered}
T\left(x_{k}, t\right)=\phi_{\text {cent }}\left(x_{k}, t\right), \quad u_{i}\left(x_{k}\right)=U_{i}^{\text {cent }}\left(x_{k}\right), \quad \sigma_{n}=q_{i}^{\text {cent }}, \\
\left\{\begin{array}{lll}
\left(v_{F}\left|\sigma_{n}\left(u_{k}\right)\right|-\left|\sigma_{T}\left(u_{k}\right)\right|\right) u_{T}=0, & \text { if }\left|\sigma_{T}\left(u_{k}\right)\right|<v_{F}\left|\sigma_{n}\left(u_{k}\right)\right|, \\
\sigma_{T} \cdot u_{t}+v_{F}\left|\sigma_{n}\left(u_{k}\right)\right|\left|u_{T}\right|=0, & \text { if }\left|\sigma_{T}\left(u_{k}\right)\right|=v_{F}\left|\sigma_{n}\left(u_{k}\right)\right|,
\end{array}\right.
\end{gathered}
$$

- on the part of boundary surface $\Gamma_{2}$, where is no contact $u_{n}<\xi_{n}, \sigma_{n}\left(u_{k}\right)=0$ we establish adiabatic a condition

$$
\lambda \frac{\partial T}{\partial \vec{n}}=0
$$

where $\sigma_{n}\left(u_{k}\right)=\sigma_{i j}\left(u_{k}\right) n_{i} n_{j}, \sigma_{T}=\sigma_{i j}\left(u_{k}\right) n_{j}-\sigma_{n}\left(u_{k}\right) n_{i}, \sigma_{i j}=2 \mu\left[\left(v H-e_{T}\right) g_{i j}+\right.$ $\left.\varepsilon_{i j}\right]-\Gamma_{i j}, \varepsilon_{i j}=1 / 2\left(\nabla_{i} u_{j}+\nabla_{j} u_{i}\right), \vec{n}-$ unit normal vector to the boundary $\Gamma_{2}, u_{n}, u_{T}-$ normal and tangent components of a vector of displacement on $\Gamma_{2}, 1 \leqslant i, j, k \leqslant 3, \xi_{n}$-normal component of a vector of displacement $\mathrm{CPB}$ on $\Gamma_{2}, U_{i}^{0}, U_{i}^{\text {cent }}\left(x_{k}\right)$ - components of a vector of displacement of the shell and central profile body, $q_{i}^{0}, q_{i}^{\text {cent }}, \phi_{0}(t), \phi_{\text {cent }}(t)$ - contact pressure and temperature (Fig. 2) accordingly on boundary surface $\Gamma_{1}($ index -0$)$ and $\Gamma_{2}$ (index $-c$ ), $v_{F}$ - coefficient of friction.

Boundary value problem (1)-(7) we solve together with the equations thermoelasticity for the central profile body (Fig. 1) and equations of balance for thin-walled thermopliable moment of the shell of rotation $[13,16,22]$. 


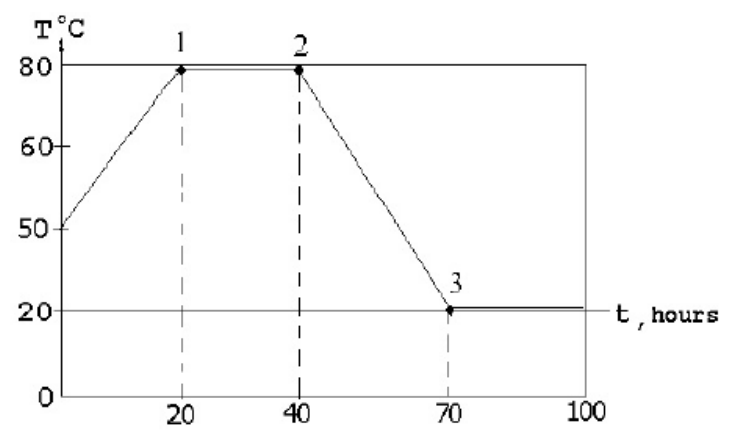

Fig. 2. The temperature change on boundary surface $\Gamma_{1}, \Gamma_{2}$

\section{Numerical studies}

The numerical solution boundary-value problem (1)-(7) we make mixed finite element method to the formulation Galerkin by approximation of required functions on cubic of a isoparametrical element Lagrang's of family of the second order in space, satisfying to a discrete condition Ladygenskay-Brezzi-Babuska [19, 23-30].

This article demonstrates a different cure-, temperature dependent approach. In general viscoelastic models can be written in integral or differential form, and the latter is chosen. This differential form is written incrementally to define the stress at the actual time step

$$
\begin{gathered}
\Delta \sigma_{i j}(t)=\sigma_{i j}(t-\Delta t) \cdot \exp \left(\Delta t / \tau_{c h r i}\right), \\
\sigma_{i j}(t)=C_{i j k l} \cdot \varepsilon_{\text {total }}+\Delta \sigma_{i j}(t) .
\end{gathered}
$$

Using this formulation, the characteristic relaxation time vector $\tau_{c h r i}$ has to be defined in the way to represent the dependency on the degree of cure [17, 19].

The following values of the main parameters were used in the accounts for numerical modelling the polymerization process FCM in the given casting form:

- for FCM: $T_{n}=50^{\circ} \mathrm{C}, \beta_{n}=0.08, c_{p}=1300 \mathrm{~J} / \mathrm{mol}, \rho=1700 \mathrm{~kg} / \mathrm{m}^{3}, K_{0}=4 \cdot 10^{7} \mathrm{1} / \mathrm{s}$, $E / R=9000^{\circ} \mathrm{C}, Q_{0}=460 \mathrm{~J} / \mathrm{mol}, \lambda=0.34 \mathrm{~W} \cdot{ }^{\circ} \mathrm{C} / \mathrm{m}, \mu_{0}=9,4 \cdot 10^{-5} \mathrm{MPa}, a_{1}=2.5$, $a_{2}=1.1 \cdot 10^{-3} 1 /{ }^{\circ} \mathrm{C}, \alpha_{t}=3.1 \cdot 10^{-5} 1 /{ }^{\circ} \mathrm{C}, \alpha_{\beta}=1 \cdot 10^{-3}, \alpha_{p}=2.0 \cdot 10^{-3}, v_{0}=0.5, R_{1}=0.6 \mathrm{~m}$, $R_{0}=0.15 \mathrm{~m}, L=3 \mathrm{~m}, v_{F}=0.3$

- for the shell: $\mu_{0}=2 \cdot 10^{4} \mathrm{MP} 0, v_{0}=0.4, h=5 \cdot 10^{-3} \mathrm{~m}, \alpha_{t}=5.0 \cdot 10^{-4} 1 /{ }^{\circ} \mathrm{C}$;

- for the central body: $\alpha_{t}=5 \cdot 10^{-6} 1 /{ }^{\circ} \mathrm{C}, \mu_{c}=1 \cdot 10^{5} \mathrm{MP0}, v=0.3$.

We consider that system: shell - FCM - a central profile body is subjected to warm-up processing on mode, submitted for Fig. 2. We shall consider at the beginning initially results numerical calculation of FCM solidification with thermo-elastic CPB.

On Fig. 3 is brought field of the temperature and degree polymerization at moments of time $t=20$ hours, 40 hours, 70 hours, corresponding to termination main stage is haved a temperature-temporary mode (heating, endurance, cooling) (Fig. 2). From result of the calculation is seen that field of the temperature and degree of cure on accounting area very lumpy (Fig. $3-a, c, d$ ). This is connected with small factor of temperature conduction.

Herewith, the maximum gradients of the temperature appear at moments of time $t=20$ hours (begin stage of thermal staticsing) and $t=70$ hours (the termination of the stage of the cooling) and form accordingly $21^{\circ} \mathrm{C}$ and $42^{\circ} \mathrm{C}$. Analysis of the distribution by flap of the temperature and 
degree of cure shows that in accounting area possible to select two subregions, prepared umbellate salient. The Evolution of average importances $T$ and $\beta$ on subregion $\mathrm{A}$ and $\mathrm{A}^{\prime}$ is brought on Fig. 4. Their analysis shows that velocities of the heating and cooling, as well as degree of polymerization FCM in them different. This brings about origin different three-dementional deformation in data subregion and, consequently, to different level of the developing stresses (Fig. 5), maximum difference which can reach $49 \%$.

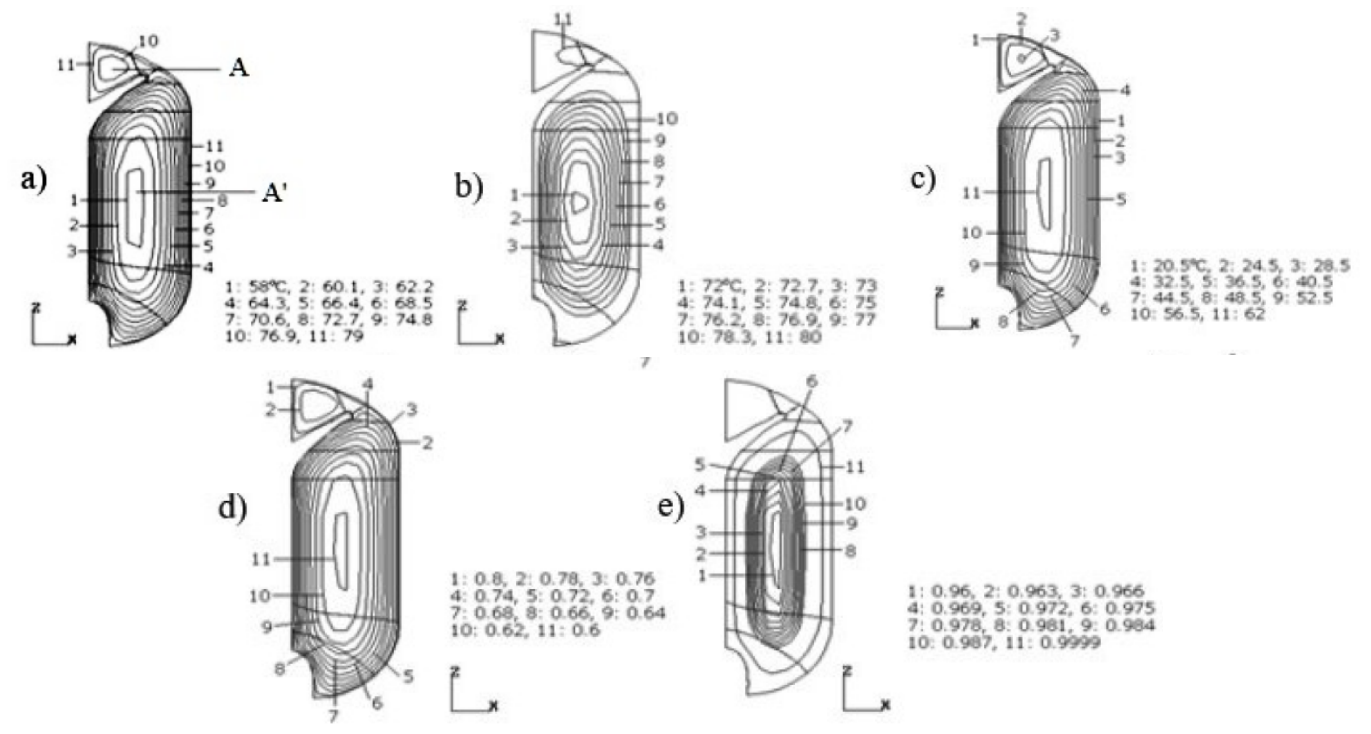

Fig. 3. Isolines of temperature in FCM at the moments of time: a) 20 hours; b) 40 hours; c) 70 hours and degrees cure FCM at the moment of time d) 20 hours; e) 40 hours

a)

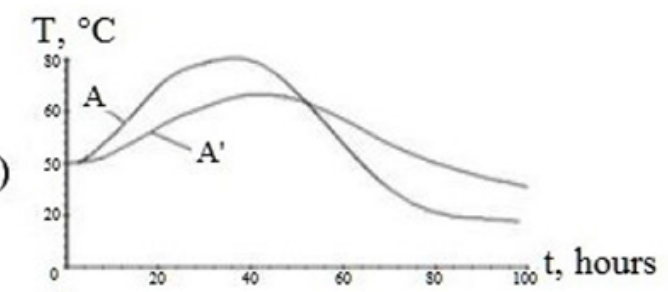

b)

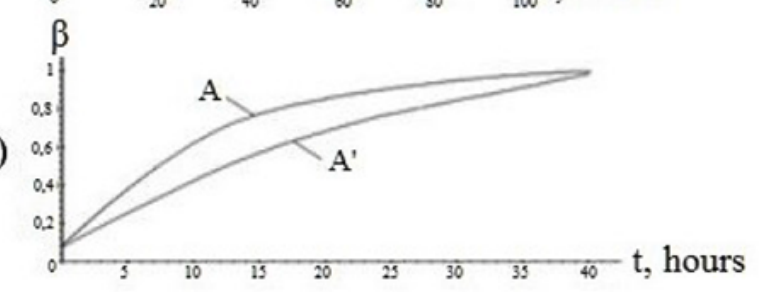

Fig. 4. Evolutions middle temperature $(T)$ and the degree of polymerization $(\beta)$ in subregion $A$ and $A^{\prime}$ (Fig. $3 a$ )

As a whole on area hydrostatic nature of the stresses (Figs. 5,6), except subregions with concentrator of the stresses (Fig. 6). We shall note that in subregions umbellate salient on his forming technological stresses increase at the average in 4.4 times that in turn brings about arising the tangential stresses. 


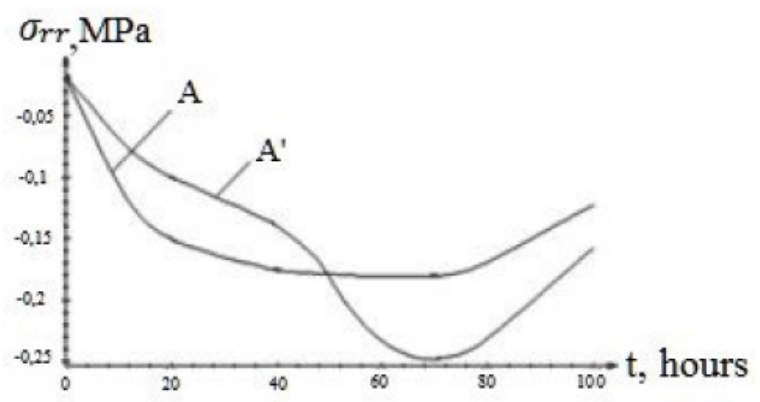

Fig. 5. Evolutions of the average radial stresses in subregion $A$ and $A^{\prime}$ (Fig. $3 a$ )

a)

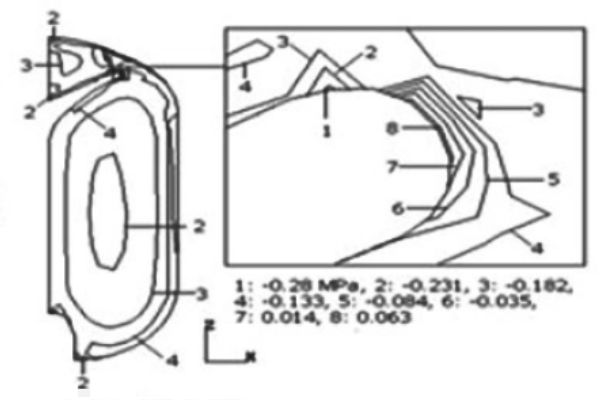

b)
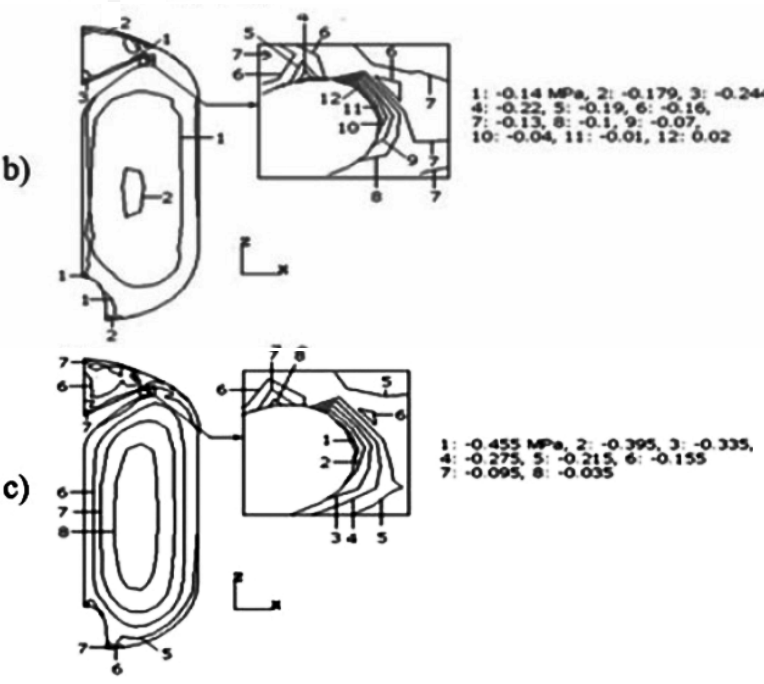

Fig. 6. Isolines of radial stresses $\sigma_{r r}$ at the moments of time: a) 20 hours; b) 40 hours; c) 70 hours

On Fig. $6 a$ is illustrated evolution of the radial stresses of the area. At initial moment of time in the whole area from initial underpressure compressing (negative) of the stresses $\sigma_{r r}$. In step of heating increase level exists in the field of compressing stresses except top umbellate salient. In top umbellate salient at moment of time $t=4$ hours. appear spraining stresses, maximum level which exists at moment of time $t=20 \mathrm{~h}$ and forms $\sigma_{r r} \approx 0.06 \mathrm{MPa}$.

In step of thermal staticsing small growing level exists in the field of compressing stresses. This is conditioned that that investment from warm-up expansion and level initial underpressure 
exceeds the value of the chemical shrinkage FCM. In top of umbellate salient value spraining stresses falls, but to moment of the termination of the stage thermal staticsing there appears small compressing stresses. Before beginning of the stage cooling material have gained the givenned properties, but reaction of solidification FCM completed.

In step of cooling shell begins to move toward central profile body and acts upon FCM. So, in him appear additional compressing stresses. On the last stage of the process of polymerization $(t=70-100$ hours $)$ reduction level exists in FCM compressing radial stresses, occurring to account of the warm-up compression FCM. Since limit to toughness highfilling incondensable composit material on compression more, than on sprain [2], the most danger in FCM present the spraining stresses. So the most probable zone of the fracture in the field of is a subregion umbellate salient (Fig. 6a).

One of the reasons of defect rise under solidification FCM are a tangent stresses. From result of the calculation follows that maximum tangent stresses appear in subregions of umbellate salient at moment begin stage of thermal staticsing ( $t=20$ hours).

The studies were carried out using the resources of the Center for Shared Use of Scientific Equipment "Center for Processing and Storage of Scientific Data of the Far Eastern Branch of the Russian Academy of Sciences", funded by the Russian Federation represented by the Ministry of Science and Higher Education of the Russian Federation under project no. 075-15-2021-663.

\section{Conclusions}

A scheme of the central coaxial body loosening in the axial direction is proposed, which allows to switch to modes with a decrease in the level of technological stresses by an order of magnitude. The average level of compressive technological stresses in the product does not exceed $0.3 \mathrm{MPa}$ and decreases to $50 \mathrm{KPa}$ during cooling. To ensure defect-free curing conditions, it is necessary to create a pressure in the system of about 8 atmospheres at the hydrodynamic stage of filling (it depends on the microstructure of the polymer composite). Temperature regimes of heating and cooling for large-sized items should not exceed 2 degrees / hour.

\section{References}

[1] A.AY.Malkin, V.P Begishev, Chemical forming of polymers, Chemistry, Moscow, 1991 (in Russian).

[2] V.V.Bolotin, A.N Vorontsov, V.B.Antokhov, The theory compression forming of products from composite of materials, Mechanics of Composite Materials, 6(1982), 1034-1042 (in Russian).

[3] B.W.Shaffe, M.Lewitsky, Termoelastic constitutive equation for chemically hardering materials, Journal of Appl. Mech., 41(1974), 652-657.

[4] D.A.Frank-Kamenecki, Diffusion and heat transfer in chemical kinetics, Science, Moscow, 1967 (in Russian).

[5] N.M.Chechilo, N.S.Enikolopayn, About structure of front polymerization of a wave and mechanism of distribution of reaction polymerization, Dokl. Acad. Sci. USSR, 214(1974), no. 5, 1131-1133 (in Russian). 
[6] N.H.Arutynayn, A.D.Drozdov, Phase transitions in elastic and viscoelastic bodies, Mechanics of Composite Materials, 1(1986), 94-102 (in Russian).

[7] L.V.Klichnikov, E.E Alaynova, B.A.Rozenberg, Method of equivalent definition of internal voltage in elastic models frontal polymerization, Mechanics of Composite Materials, 31(1995), 3-9 (in Russian).

[8] V.V.Moskvitin, Resistance viscoelastic of materials, Science, Moscow, 1972 (in Russian).

[9] K.A.Chekhonin, A.N.Baklanov, The decision of primary tasks of the theory of elasticity at polymerization of incompressible environments, Science, Vladivostok, 1998 (in Russian).

[10] A.M.Lipanov, M.Y Al'es, O.I.Evstefiev, Numerical modeling to an intense - deformated status polymerization of polymeric systems, J. High-molecular of connection, 33(1991), no. 1, 52-59 (in Russian).

[11] L.A.Golotina, V.P.Matveenko, I.N.Shardakov, Analysis of deformation process characteristics in amorphous-crystalline polymers, Mechanics of Solids, 47(2012), 634-640.

DOI: $10.3103 /$ S0025654412060040

[12] K.A.Chekhonin, R.N.Pilipchuk, Modeling polymerization press-forms with the account incompressibility or near-incompressibility of the fuel, Science, Vladivostok, 1998 (in Russian).

[13] A.N.Baklanov, Mathematical modeling volumetric solidification higt-filled of a com-posite in the press-forms, Ph. D. Tesis, The Khabarovsk State Technical University, Khabarovsk, 2000 (in Russian).

[14] R.N.Pilipchuk, Mathematical modeling compression polymerization incompressible or nearly incompressible composite of materials. Ph. D. Tesis, The Khabarovsk State Technical University, Khabarovsk, 2000 (in Russian).

[15] V.K.Bulgakov, K.A.Chekhonin, I.I.Potapov, A.N.Baklanov, The analysis of the threedimensional FCM press-form at a stage solidification, J. Mathematical modeling, 3(1997), 181-192 (in Russian).

[16] K.A.Chekhonin,A.N.Baklanov, Modeling of the stressedly-deformed conditions incompressible solidification of a polymeric material in conditions of contact with moment by the thin-walled shell of rotation, J. Mathematical modeling, 4(1998) 40-66 (in Russian).

[17] V.K.Bulgakov, K.A.Chekhonin, Modeling of a 3D Problem of compression forming system "Composite shell - low compressible consolidating filler", J. Mathematical Modeling, 4(2002), 121-131 (in Russian).

[18] I.N.Shardakov, V.P.Matveyenko, N.V.Pistsov, V.P.Beghishev, Simulation of thermomechanical processen in crystallising polymer, Polym. Eng. and Sci, 37(1997), no. 8, 1270-1279.

[19] K.A.Chekhonin, The Essential priciples for theory curing process solid propellant grain, Vestnik ITPS, 12(2016), no. 1, 131-145 (in Russian).

[20] L.R.Herrmann, Elasticity equations for incompressible and nearly incompressible materials by a variational theorem, AIAA J., 3(1965), 1896-1900. 
[21] N.Kikuchi, J.T.Oden, Contact problem in elasticity study of variational inequalities and finite element methods, SIAM, Philadelphia, 1988.

[22] V.V.Novogilov, The theory of thin shells, Sudpromgis, Moscow, 1951 (in Russian).

[23] V.Girault, P-A.Raviart, Finite element methods for Navier-Stokes equations, SpringerVerlag, Berlin, 1986.

[24] E.G.Diaykonov, Minimization of computing work. Asymptotically optimum algorithms for elliptic tasks, Science, Moscow, 1989 (in Russian).

[25] F.Brezzi, M.Fortin, Mixed and hybrid finite element method, Springer, New York, 1991.

[26] K.A.Chekhonin, A.N.Baklanov, About some finite element approximations of the mixed type for incompressible or near-incompressible environments in $R^{3}$, Science, Vladivostok, 1998 (in Russian).

[27] R.Glowinski, O.Pironneau, Finite element method for Navier-Stokes equations, Annu. Rev. Fluid Mech., 24(1992), 167-204.

[28] V.K.Bulgakov, K.A.Chekhonin, The Biseline theory mixed finite element method, Khabarovsk State Technical University, Khabarovsk, 1999 (in Russian).

[29] Y.Saad, Iterative methods for sparse linear systems, PWS Publishing Company, 1996.

[30] K.A.Chekhonin, P.A.Sukhinin, Numerical modeling of filling axisymetric of the channel nonlinear viscoplastic by a liquid in view of wall-boundary-effect, Engineering Phys. J., 72(1999), no. 5, 881-885 (in Russian).

\title{
Численное моделирование компрессионного отверждения высоконаполненного полимерного материала
}

Константин А. Чехонин

Виктор Д. Власенко

Вычислительный центр ДВО РАН Хабаровск, Российская Федерация

\begin{abstract}
Аннотация. В статье представлены феноменологические определяющие соотношения для моделирования компрессионного отверждения высоконаполненной полимерной среды, полученные в рамках механики почти несжимаемого вязкоупругого твердого тела с использованием модифицированного вариационного принципа Геррмана. В основе соотношений лежит представление среды в виде композиции жидкотекучего и отвержденного материала с учетом истории непрерывного зарождения и деформирования новой фазы в интервале температур фазовых превращений. В процессе производства различные механизмы вызывают в изделии деформации и напряжения. Эти механизмы зависят от теплового расширения, усадки, нелинейных вязкоупругих свойств композита и изменения локальных температур. В критических случаях эти технологические напряжения могут привести к накоплению повреждений в композите (отслоение матрицы полимера от дисперсного наполнителя) вплоть до разрушения материала. Разработан устойчивый численный алгоритм решения задачи на основе метода конечных элементов. Проведено численное исследование эволюции технологических напряжений и деформаций при химическом компрессионном формовании в осесимметричных оболочечных пресс-формах. Исследована особенность эволюции технологических напряжений в подобластях со сложной геометрией.
\end{abstract}

Ключевые слова: полимеризация, высоконаполненный полимер, метод конечных элементов, напряжения отверждения, вязкоупругость, вариационный принцип Геррмана. 